\title{
Os desafios da intervenção fonoaudiológica no aleitamento materno: revisão
}

\section{integrativa}

\author{
The challenges of speech therapy intervention in breastfeeding: an integrative review \\ Los desafíos de la intervención logopédica en la lactancia materna: una revisión integradora
}

Recebido: 08/01/2021 | Revisado: 11/01/2021 | Aceito: 13/01/2021 | Publicado: 17/01/2021

\author{
Vanessa Karlla de Sousa Franklin \\ ORCID: https://orcid.org/0000-0003-4720-4142 \\ Faculdade de Ensino Superior do Piauí, Brasil \\ E-mail: vkarllafranklin@gmail.com \\ Priscila Figueiredo Cruz Ramos \\ ORCID: https://orcid.org/0000-0002-8188-3559 \\ Faculdade de Ensino Superior do Piauí, Brasil \\ E-mail: priscilaafc@hotmail.com
}

\begin{abstract}
Resumo
O presente estudo teve como objetivo principal descrever os principais fatores que interferem no aleitamento materno com foco nas disfunções orais e demonstrar como a intervenção fonoaudiológica é primordial nesse processo. A metodologia utilizada consistiu em uma revisão integrativa da literatura através da base de dados PubMed, onde foram incluídos artigos e estudos referentes aos últimos 5 anos de publicação (2015 a 2020), nos idiomas português e inglês que abordassem a temática referente ao estudo em questão. Os estudos corroboram que a atuação fonoaudiológica na amamentação proporciona a parceria que contribui para o desenvolvimento materno infantil. Contudo, existe a necessidade de detectar precocemente os fatores associados para intervenção e manejo adequado. Assim, conclui-se que o trabalho do fonoaudiólogo junto às mães e bebês na maternidade faz-se de fundamental importância, principalmente para detectar precocemente os desafios para o estabelecimento do aleitamento materno saudável, e cabe a esse profissional atender, ouvir e transmitir às mães informações relacionadas tanto ao aleitamento como para as implicações no bom desenvolvimento das estruturas orais dos recém-nascidos.
\end{abstract}

Palavras-chave: Aleitamento materno; Fonoaudiologia; Serviços de saúde materno-infantil; Relações mãe-filho.

\begin{abstract}
The present study aimed to describe the main factors that interfere in breastfeeding with a focus on oral disorders and demonstrate how the speech therapy intervention is essential in this process. The methodology used consisted of an integrative review of the literature through the PubMed database, which included articles and studies referring to the last 5 years of publication (2015 to 2020), in Portuguese and English that addressed the theme related to the study in question. The studies corroborate that the speech therapy performance in breastfeeding provides the partnership that contributes to the maternal and child development. However, there is a need to detect the associated factors for intervention and proper management early. Thus, it is concluded that the work of the speech therapist with mothers and babies in the maternity ward is of fundamental importance, mainly to detect early the challenges for the establishment of healthy breastfeeding, and it is up to this professional to attend, listen and transmit to mothers information related to both breastfeeding and the implications for the proper development of newborns' oral structures.
\end{abstract}

Keywords: Breastfeeding; Speech therapy; Maternal and child health services; Mother-child relations.

\section{Resumen}

El presente estudio tuvo como objetivo describir los principales factores que interfieren en la lactancia materna con un enfoque en los trastornos bucales y demostrar cómo la intervención logopédica es fundamental en este proceso. La metodología utilizada consistió en una revisión integradora de la literatura a través de la base de datos PubMed, que incluyó artículos y estudios referidos a los últimos 5 años de publicación (2015 a 2020), en portugués e inglés, que abordaron la temática relacionada con el estudio en cuestión. Los estudios corroboran que las actividades de logopedia en la lactancia materna proporcionan la asociación que contribuye al desarrollo materno e infantil. Sin embargo, es necesario detectar precozmente los factores asociados para una intervención y un manejo adecuado. Así, se concluye que la actuación del logopeda con las madres y los bebés en la maternidad es de fundamental importancia, principalmente para detectar precozmente los desafíos para el establecimiento de una lactancia materna saludable, y le corresponde a este profesional atender, escuchar y transmitir información relacionada con la lactancia materna. y las implicaciones para el correcto desarrollo de las estructuras bucales del recién nacido. 
Palabras clave: Lactancia Materna; Terapia del lenguaje; Servicios de salud maternoinfantil; Relaciones madre-hijo.

\section{Introdução}

O Aleitamento Materno (AM) é a fase na qual o bebê se alimenta total ou parcialmente do leite da mãe. (Bezzuti \& Giustina, 2017). Essa fase tão importante tanto sob o ponto de vista psicológico quanto sob o afetivo, proporciona o vínculo mãe-bebê, que se inicia durante a gestação e se fortalece com o aleitamento, dando origem ao bem-estar, segurança e afetividade do bebê. (Kurtz et al., 2015). Promovendo ainda as saúdes mental, psíquica e físicas da criança e da mulher que amamenta. (Pontes et al., 2013). Além de ser, de acordo com a Organização Mundial da Saúde (OMS), um dos maiores aliados no combate à mortalidade infantil, reduzindo no Brasil, a taxa de mortes infantis em $47 \%$ na última década.

Para o estabelecimento do AM os primeiros dias de vida após o nascimento são fundamentais (Medeiros et al., 2017). Ao sugar o leite materno, o bebê estabelece o padrão natural de respiração, postura correta da língua, e promove o crescimento facial harmônico (Rodrigues et al., 2017). Além disso, durante a sucção no seio materno, os músculos envolvidos são estimulados, aumentam o tônus e adquirem uma postura adequada para exercer a função de mastigação futuramente (Martins et al., 2012).

Entretanto, há fatores que podem interferir nesse processo, favorecendo o desmame precoce. (Valério; Araújo \& Coutinho, 2010). Alguns desses fatores estão diretamente relacionados à mãe, como as características de sua personalidade, sua atitude frente à situação de amamentar, inexperiência e dores (Araújo et al., 2008). E outros especificamente ao RecémNascido (RN), como as alterações no sistema motor-oral, denominadas disfunções orais (Medeiros et al., 2017).

As disfunções orais são fatores interferentes para o estabelecimento do aleitamento materno relacionados ao bebê e podem gerar traumas mamilares, pouco ganho de peso do bebê e até desmame precoce. (Valério, Araújo \& Coutinho, 2010). Entre as causas de alterações na sucção do bebê na mamada, estão: baixo peso ao nascer (em especial prematuridade), distúrbios metabólicos, alterações neurológicas, intercorrências clínicas, síndromes e anomalias congênitas (fissuras submucosas, fissuras labiopalatais, anquiloglossia e laringomalacia). (Sanches, 2004).

Em consideração as principais dificuldades em relação ao AM os profissionais de saúde podem contribuir, reconhecendo e intervindo precocemente através de capacitação para a avaliação da mamada e para o manejo clínico adequado das disfunções orais (Sanches, 2004). Faz-se necessário conhecimento sobre anatomia e neurofisiologia oral do bebê, bem como experiência no manejo clínico da amamentação, tornando-se imprescindível a participação de um fonoaudiólogo em equipe multidisciplinar, enfatizando os benefícios do AM no desenvolvimento das estruturas orofaciais, da fala e da linguagem (Scheeren et al., 2012).

O trabalho do fonoaudiólogo faz-se de fundamental importância junto às mães e bebês na maternidade, e cabe a esse profissional atender, ouvir e transmitir às mães informações relacionadas tanto ao aleitamento como para as implicações no bom desenvolvimento das estruturas orais (Medeiros, Batista \& Barreto, 2015). Sendo o profissional da saúde que está diretamente ligado às funções estomatognáticas, no que envolve a mastigação, sucção, deglutição, respiração e fala, o fonoaudiólogo está habilitado para intervir nas desordens dessas funções, assim como no sistema motor oral do bebê, identificando-as precocemente e intervindo (Medeiros, Batista \& Barreto, 2015).

No entanto, ainda nos deparamos com baixo índice de fonoaudiólogos inseridos nas maternidades e carência de estudos que comprovem o conhecimento das mães sobre o que a fonoaudiologia tem a ver com a amamentação, e de que forma contribui para a saúde materno infantil (Neves, Aguiar \& Andrade, 2012). 
Baseado nesse fato, o objetivo principal da presente pesquisa consiste em descrever os principais fatores que interferem no aleitamento materno com foco nas disfunções orais, demonstrando como a intervenção fonoaudiológica é primordial no processo de aleitamento materno.

\section{Metodologia}

O estudo trata-se de uma revisão integrativa que, de acordo com Mendes, Silveira \& Galvão (2008), consiste na construção de uma análise ampla da literatura, contribuindo assim, para discussões sobre métodos e resultados de pesquisas, assim como reflexões sobre a realização de futuros estudos. De método qualitativo no qual é importante a interpretação por parte do pesquisador com suas opiniões sobre o fenômeno em estudo. (Pereira et al., 2018).

Para a elaboração do estudo delimitou-se as seguintes etapas percorridas:

Primeira fase: definição das palavras-chaves de acordo com os termos DECS (Descritores em Ciências da Saúde) nas línguas portuguesa e inglesa, resultando respectivamente em: Aleitamento Materno (Breast Feeding), Fonoaudiologia (Speech Therapy) Serviços de Saúde Materno-Infantil (Maternal-Child Health Services) e Relações Mãe-Filho (Mother-Child Relations).

$\mathrm{Na}$ segunda fase, por meio da base de dados PubMed foram realizadas as buscas de artigos científicos, onde foram incluídos artigos publicados entre os anos 2015 a 2020, nos idiomas português e inglês que abordassem a temática referente ao estudo em questão e excluídos os estudos com indisponibilidade de acesso, artigos/trabalhos incompletos, duplicados, fora do recorte temporal definido e que não atendiam à temática.

Após as buscas dos estudos com as palavras-chaves definidas, iniciou-se então a seleção dos estudos. Dos 325 artigos encontrados, 263 artigos foram excluídos por apresentarem títulos e resumos incoerentes ao tema. 20 artigos foram préselecionados para análise metodológica, dos quais 13 foram excluídos pelos seguintes critérios de exclusão: indisponibilidade de acesso, artigos/trabalhos incompletos, resumos, textos na forma de projetos, estarem fora do recorte temporal definido nos critérios de inclusão, textos duplicados e todos os artigos que não atendiam à temática. Permanecendo 7 artigos que contemplavam os critérios de elegibilidade e foram incluídos no estudo. (Figura 1).

$\mathrm{Na}$ quarta fase os estudos foram analisados para a verificação de sua autenticidade, qualidade metodológica, importância das informações e representatividade. Para a análise e posterior síntese dos artigos que atenderam aos critérios de inclusão utilizou-se uma hierarquia das evidências, segundo o delineamento da pesquisa (Souza, Silva \& Carvalho, 2010):

•Nível I: evidências resultantes da meta-análise de múltiplos estudos clínicos controlados e randomizados;

-Nível II: evidências obtidas em estudos individuais com delineamento experimental;

-Nível III: evidências de estudos quase-experimentais;

•Nível IV: evidências de estudos descritivos (não-experimentais) ou com abordagem qualitativa;

-Nível V: evidências provenientes de relatos de caso ou de experiência;

•Nível VI: evidências baseadas em opiniões de especialistas. (Quadro 1).

A quinta fase consistiu na realização da interpretação e discussão dos dados e por fim, na sexta fase, foi demonstrada a revisão e síntese do conhecimento que foram vistas em artigos analisados sobre a temática. A análise dos dados foi realizada, baseada nos artigos selecionados, em que foi possível observar, descrever e qualificar os dados, para reunir o conhecimento produzido através da temática nessa revisão. (Souza, Silva \& Carvalho, 2010). 


\section{Resultados}

As pesquisas resultaram em 84 artigos com o cruzamento dos descritores Aleitamento materno AND Serviços de saúde materno-infantil; 232 com Aleitamento materno AND Relação mãe-filho e 9 com os descritores Aleitamento Materno AND Fonoaudiologia, totalizando 325 artigos.

O resultado das buscas de artigos conforme a base de dados, e os critérios de inclusão podem ser vistos na Figura 1:

Figura 1 - Fluxograma do processo de identificação e seleção dos artigos de acordo com o método PRISMA.

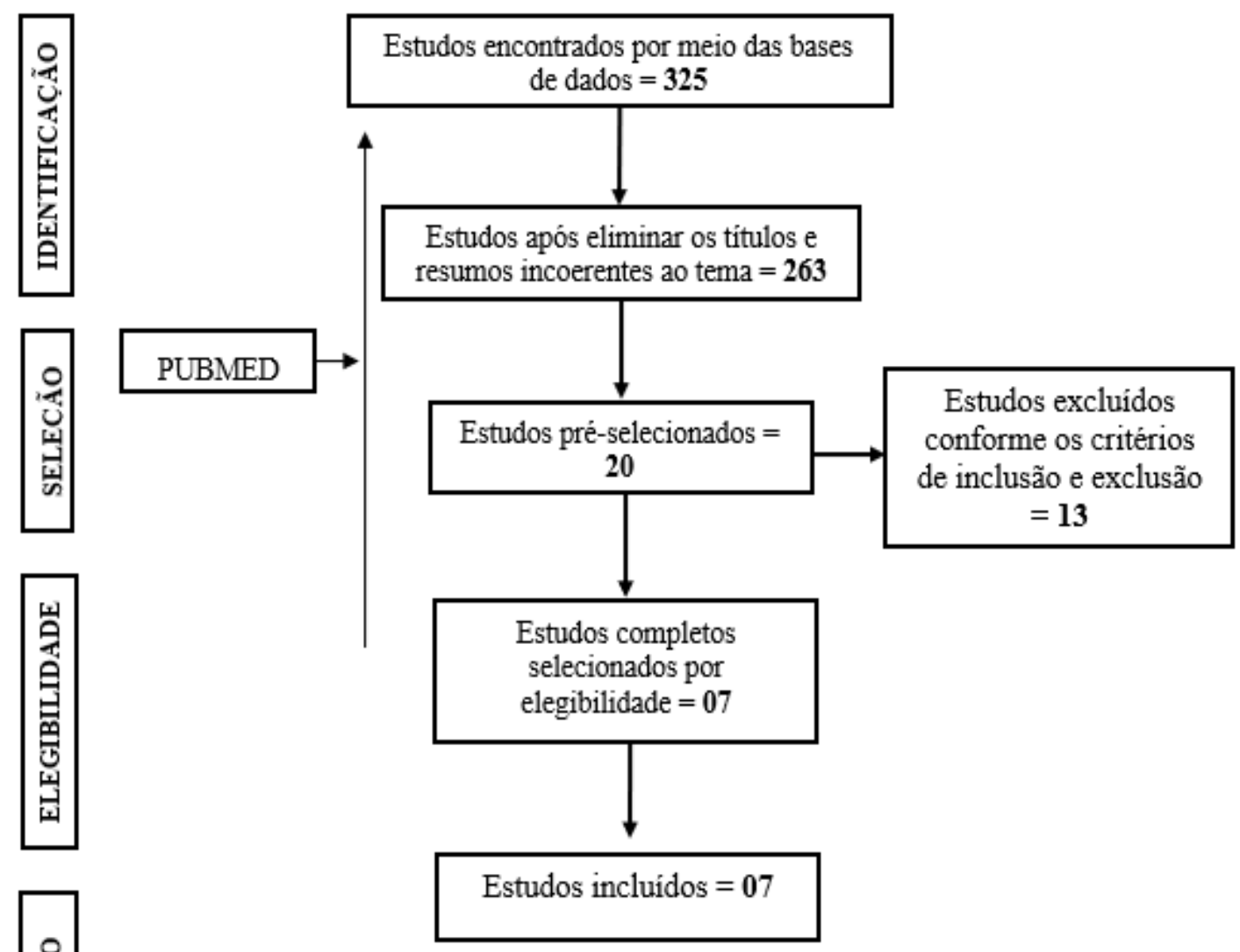

Fonte: Autores.

Assim, com o objetivo de extrair as informações chaves de cada artigo selecionado, utilizou-se o seguinte instrumento de coleta de dados: 
Quadro 1 - Instrumento de Coleta de Dados dos Artigos PubMed.

\begin{tabular}{|c|c|c|c|c|c|c|}
\hline PERIÓDICO & ANO & LOCAL & TÍTULO & $\begin{array}{c}\text { TIPO DE } \\
\text { PESQUISA }\end{array}$ & $\begin{array}{c}\text { TIPO DE } \\
\text { PRODUÇÃO }\end{array}$ & $\begin{array}{c}\text { NÍVEL DE } \\
\text { EVIDÊNCIA }\end{array}$ \\
\hline $\begin{array}{l}\text { Revista de } \\
\text { Atenção à } \\
\text { Saúde }\end{array}$ & 2015 & $\mathrm{RS}$ & $\begin{array}{l}\text { Promoção ao } \\
\text { aleitamento } \\
\text { materno em um } \\
\text { contexto } \\
\text { interdisciplinar }\end{array}$ & $\begin{array}{l}\text { Revisão de } \\
\text { Literatura }\end{array}$ & $\begin{array}{l}\text { Artigo de } \\
\text { Revisão }\end{array}$ & VI \\
\hline $\begin{array}{c}\text { Revista Paulista } \\
\text { de Pediatria }\end{array}$ & 2015 & MG & $\begin{array}{c}\text { Apoio ao } \\
\text { aleitamento } \\
\text { materno pelos } \\
\text { profissionais de } \\
\text { saúde }\end{array}$ & $\begin{array}{l}\text { Revisão } \\
\text { Integrativa }\end{array}$ & $\begin{array}{l}\text { Artigo de } \\
\text { Revisão }\end{array}$ & VI \\
\hline $\begin{array}{c}\text { Sociedade } \\
\text { Brasileira de } \\
\text { Fonoaudiologia }\end{array}$ & 2015 & BA & $\begin{array}{l}\text { Acompanhamento } \\
\text { da efetividade do } \\
\text { aleitamento } \\
\text { materno após } 24 \\
\text { horas de } \\
\text { intervenção } \\
\text { fonoaudiológica. }\end{array}$ & Qualitativa & $\begin{array}{l}\text { Artigo } \\
\text { Original }\end{array}$ & IV \\
\hline $\begin{array}{c}\text { Audiology } \\
\text { Communication } \\
\text { Research }\end{array}$ & 2015 & SE & $\begin{array}{c}\text { Aleitamento } \\
\text { materno e } \\
\text { aspectos } \\
\text { fonoaudiológicos: } \\
\text { conhecimento e } \\
\text { aceitação de mães } \\
\text { de uma } \\
\text { maternidade }\end{array}$ & $\begin{array}{l}\text { Intervencionista } \\
\text { e Comparativo }\end{array}$ & $\begin{array}{l}\text { Artigo } \\
\text { Original }\end{array}$ & III \\
\hline $\begin{array}{c}\text { Audiology } \\
\text { Comunnication } \\
\text { Research }\end{array}$ & 2017 & SE & $\begin{array}{l}\text { Acompanhamento } \\
\text { fonoaudiológico } \\
\text { do aleitamento } \\
\text { materno em } \\
\text { recém-nascidos } \\
\text { nas primeiras } \\
\text { horas de vida }\end{array}$ & Qualitativa & $\begin{array}{l}\text { Artigo } \\
\text { Original }\end{array}$ & IV \\
\hline $\begin{array}{c}\text { Revista Digital } \\
\text { Acadêmica } \\
\text { CREFONO1 }\end{array}$ & 2017 & RJ & $\begin{array}{l}\text { O fonoaudiólogo } \\
\text { no incentivo do } \\
\text { aleitamento } \\
\text { materno nas } \\
\text { maternidades. }\end{array}$ & Qualitativa & $\begin{array}{l}\text { Artigo de } \\
\text { Revisão }\end{array}$ & IV \\
\hline & 2017 & $\mathrm{SC}$ & $\begin{array}{l}\text { A importância do } \\
\text { aleitamento } \\
\text { materno } \\
\text { exclusivo até os } \\
\text { seis meses de } \\
\text { idade }\end{array}$ & Qualitativa & $\begin{array}{l}\text { Artigo de } \\
\text { Revisão }\end{array}$ & VI \\
\hline
\end{tabular}

Fonte: Rodrigues, et al., (2017)

Evidenciou-se na amostra o predomínio de artigos qualitativos e revisões, relacionadas ao recorte temporal de 2015 a 2020. Ao tipo de pesquisa do recorte temporal, temos evidenciado 04 do tipo qualitativa, 01 intervencionista comparativo, 01 revisão integrativa e 01 revisão de literatura. 
Quanto aos periódicos, foram identificados 02 da Revista Audiology, 01 da Revista Digital Acadêmica, 01 da Sociedade Brasileira de Fonoaudiologia, 01 da Revista Paulista de Pediatria, 01 da Revista de Atenção à Saúde e 01 não foi identificado qual o periódico.

Os artigos tiveram como sujeitos da pesquisa mães, recém-nascidos e profissionais de fonoaudiologia e os níveis de evidências dos estudos foram classificados como III: evidências de estudos quase-experimentais. IV: evidências de estudos descritivos (não-experimentais) ou com abordagem qualitativa; e VI: evidências baseadas em opiniões de especialistas.

Para a síntese dos artigos que foram incluídos na revisão integrativa, utilizou-se um quadro especialmente elaborado pelos autores (2020), que teve como objetivo extrair as informações chaves de cada artigo selecionado. (Quadro 2)

A apresentação dos resultados e discussão dos dados obtidos foi feita de forma descritiva, possibilitando ao leitor a avaliação da aplicabilidade da revisão integrativa elaborada:

Quadro 2 - Síntese dos artigos incluídos no estudo.

\begin{tabular}{|c|c|c|c|}
\hline AUTOR/ANO & OBJETIVO & RESULTADOS & CONCLUSÕES \\
\hline $\begin{array}{l}\text { KURTZ, et al. } \\
\qquad(2015)\end{array}$ & $\begin{array}{l}\text { Mostrar que a promoção ao } \\
\text { aleitamento materno deve ser } \\
\text { realizada por qualquer } \\
\text { profissional da área da saúde } \\
\text { que tenha acesso no } \\
\text { seguimento do bebê desde o } \\
\text { pré-natal, enfatizando as } \\
\text { ações da fonoaudiologia e da } \\
\text { odontologia. }\end{array}$ & $\begin{array}{l}\text { A temática da amamentação } \\
\text { e o trabalho em unidade de } \\
\text { terapia intensiva neonatal e } \\
\text { em alojamento conjunto } \\
\text { abrem portas para que a } \\
\text { fonoaudiologia e a } \\
\text { odontologia insiram suas } \\
\text { ações e construam um co- } \\
\text { nhecimento próprio, } \\
\text { compartilhando-o com as } \\
\text { demais áreas da saúde } \\
\text { envolvidas na promoção de } \\
\text { saúde materno-infantil. }\end{array}$ & $\begin{array}{l}\text { A fonoaudiologia } \\
\text { odontologia estão } \\
\text { devidamente capacitadas nas } \\
\text { orientações dos aspectos } \\
\text { relacionados ao sistema } \\
\text { estomatognático, o que pode } \\
\text { diminuir problemas de } \\
\text { fonação, oclusão dentária, } \\
\text { respiração, motricidade } \\
\text { orofacial e deglutição, e, } \\
\text { inseridas em ações de } \\
\text { equipes interdisciplinares } \\
\text { capacitadas e treinadas, são } \\
\text { mais eficazes em promover a } \\
\text { saúde materno-infantil. }\end{array}$ \\
\hline $\begin{array}{c}\text { ALMEIDA, LUZ e UED, } \\
(2015)\end{array}$ & \begin{tabular}{lllr} 
Avaliar a & \multicolumn{2}{c}{ prática } & de \\
profissionais de saúde & na \\
promoção e & no apoio à \\
amamentação. & &
\end{tabular} & $\begin{array}{l}\text { A pesquisa revelou que a } \\
\text { amamentação é um desafio } \\
\text { para o profissional de saúde, } \\
\text { independentemente da área } \\
\text { de atuação, uma vez que ele } \\
\text { se depara com uma demanda } \\
\text { para a qual não foi preparado } \\
\text { e que exige sensibilidade e } \\
\text { habilidade em seu trato. }\end{array}$ & $\begin{array}{l}\text { Os profissionais de saúde } \\
\text { precisam ser mais bem } \\
\text { capacitados para trabalhar } \\
\text { com a promoção do } \\
\text { aleitamento materno, seja por } \\
\text { meio das instituições de } \\
\text { ensino e formação, seja por } \\
\text { gestores da saúde, a fim de } \\
\text { consolidar } \\
\text { multiprofissionais } \\
\text { comprometidas com a saúde } \\
\text { materno-infantil. }\end{array}$ \\
\hline \multirow[t]{2}{*}{$\begin{array}{l}\text { MEDEIROS et al., } \\
\text { (2015) }\end{array}$} & $\begin{array}{l}\text { Verificar a efetividade da } \\
\text { amamentação após } 24 \text { horas } \\
\text { da intervenção } \\
\text { fonoaudiológica. }\end{array}$ & $\begin{array}{l}\text { Foi possível perceber que } \\
\text { para o aleitamento } \\
\text { materno ser considerado } \\
\text { efetivo é necessário que as } \\
\text { condições clínicas, } \\
\text { anatômicas e subjetivas da } \\
\text { díade sejam favoráveis e que } \\
\text { as lactantes possuam } \\
\text { conhecimento necessário } \\
\text { para lidar com os diferentes } \\
\text { desafios que possam } \\
\text { surgir durante este processo. }\end{array}$ & $\begin{array}{l}\text { A partir das intervenções foi } \\
\text { possível perceber os aspectos } \\
\text { que podem } \\
\text { influenciar negativamente no } \\
\text { sucesso da amamentação. O } \\
\text { apoio } \\
\text { de profissionais da saúde } \\
\text { logo nas primeiras horas de } \\
\text { vida do recém-nascido } \\
\text { mostrou-se fundamental para } \\
\text { que a amamentação seja bem } \\
\text { sucedida. }\end{array}$ \\
\hline & $\begin{array}{l}\text { Investigar o conhecimento de } \\
\text { mães sobre aleitamento }\end{array}$ & Foi realizado o teste de & Faz-se fundamental \\
\hline
\end{tabular}




\begin{tabular}{|c|c|c|c|}
\hline $\begin{array}{c}\text { MEDEIROS, BATISTA e } \\
\text { BARRETO, } \\
(2015)\end{array}$ & $\begin{array}{l}\text { materno e aspectos } \\
\text { fonoaudiológicos, } \\
\text { comparando mães internadas } \\
\text { na Unidade Canguru e no } \\
\text { Alojamento Conjunto, } \\
\text { considerando tempo de } \\
\text { internação; e verificar a } \\
\text { aceitação sobre a intervenção } \\
\text { grupal realizada. }\end{array}$ & $\begin{array}{lr}\begin{array}{l}\text { assertividade } \\
\text { enfocando }\end{array} & \text { aspectos } \\
\text { aleitamento } & \text { materno, } \\
\text { linguagem, } & \text { motricidade } \\
\text { orofacial/fala e audição. Não } \\
\text { houve diferença entre tempo } \\
\text { de } \quad \text { internação } \\
\text { conhecimento }\end{array}$ & $\begin{array}{l}\text { discussão de como as mães } \\
\text { têm percebido a relação entre } \\
\text { saúde fonoaudiológica e } \\
\text { aleitamento materno. A } \\
\text { atividade de educação em } \\
\text { saúde proporcionou acesso à } \\
\text { informação, independente do } \\
\text { tempo e tipo de internação } \\
\text { dos sujeitos envolvidos. A } \\
\text { boa aceitabilidade da } \\
\text { intervenção permitiu inferir } \\
\text { sobre a viabilidade de serem } \\
\text { ampliadas práticas dessa } \\
\text { natureza no ambiente } \\
\text { hospitalar. }\end{array}$ \\
\hline RODRIGUES et al., (2017) & $\begin{array}{l}\text { Consiste no objetivo de } \\
\text { identificar a contribuição do } \\
\text { fonoaudiólogo } \\
\text { incentivo ao ara a } \\
\text { materno. }\end{array}$ & $\begin{array}{l}\text { O fonoaudiólogo tem } \\
\text { atuação direta nos primeiros } \\
\text { dias de vida do RN, no papel } \\
\text { de estimular o aleitamento } \\
\text { materno para que, quando a } \\
\text { criança alcançar a linguagem } \\
\text { oral, muitos problemas de } \\
\text { comunicação venham ser } \\
\text { evitados ou minimizados. }\end{array}$ & $\begin{array}{l}\text { A Fonoaudiologia, embora } \\
\text { seja uma ciência muito nova } \\
\text { com atuação muito recente } \\
\text { em âmbito hospitalar, que } \\
\text { tem mostrado a eficiência e } \\
\text { capaz quando o assunto é } \\
\text { Aleitamento Materno. Desde } \\
\text { a fase do pré-natal até o } \\
\text { momento da alta hospitalar, } \\
\text { o fonoaudiólogo vem } \\
\text { desempenhando um } \\
\text { importante papel, tanto na } \\
\text { promoção do aleitamento } \\
\text { materno, quanto na } \\
\text { prevenção do desmame } \\
\text { precoce. }\end{array}$ \\
\hline $\begin{array}{l}\text { BEZUTTI e GIUSTINA, } \\
(2017)\end{array}$ & 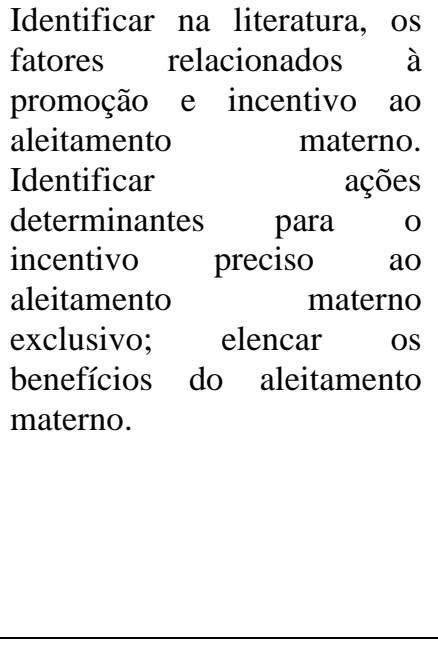 & $\begin{array}{l}\text { Detectou- se que os filhos de } \\
\text { mães adolescentes ingerem } \\
\text { significativamente menos } \\
\text { leite materno que filhos de } \\
\text { mães adultas, elas preferem } \\
\text { amamentá-los através de } \\
\text { mamadeiras para que, } \\
\text { segundo elas, não deforme as } \\
\text { mamas. }\end{array}$ & $\begin{array}{l}\text { Frente aos benefícios } \\
\text { evidenciados, pela prática do } \\
\text { aleitamento } r \text { materno } \\
\text { exclusivo, à saúde da criança } \\
\text { e da mãe e considerando a } \\
\text { necessidade de buscar } \\
\text { indicadores sobre } \\
\text { amamentação é que se deu } \\
\text { essa pesquisa. Os resultados } \\
\text { obtidos podem nos guiar para } \\
\text { estratégias políticas locais de } \\
\text { promoção do aleitamento } \\
\text { materno, além de formar um } \\
\text { banco de dados para } \\
\text { monitoramento dos } \\
\text { municípios brasileiros. }\end{array}$ \\
\hline
\end{tabular}

Fonte: Autores (2020)

\section{Discussão}

A pesquisa investigou os desafios enfrentados por mães e bebês relacionadas ao aleitamento materno, com foco nas alterações do sistema motor-oral do recém-nascido e como a intervenção fonoaudiológica se faz essencial no manejo clínico da amamentação e nas alterações do sistema motor-oral. 
Os estudos analisados demonstram que o Aleitamento Materno (AM) proporciona para o bebê não somente benefícios nutricionais, imunológicos e afetivos, mas também o adequado desenvolvimento dos sistemas cognitivo e estomatognático, proporcionando correto padrão respiratório por usar adequadamente a função de sucção e promovendo um adequado desenvolvimento craniofacial através da ação muscular. Além de prevenir a instalação de hábitos orais deletérios como o uso de chupeta e sucção digital e estimular o desenvolvimento da audição e da linguagem. (Medeiros et al., 2017).

De acordo com a pesquisa de Bezutti e Giustina, (2017), proporciona também vários benefícios para as mães, que ao amamentar, apresentam por exemplo, diminuição do volume do útero, perda de peso mais rápidas e tornam-se menos propensas a hemorragias pós-parto, anemia e doenças como câncer de mama e ovário.

No entanto, a prática do aleitamento materno caracteriza-se também por ser um período desafiador, que traz consigo muitas dúvidas e inseguranças, sendo muitas vezes um processo doloroso, que depende tanto de condições clínicas e anatômicas mãe-recém-nascido, como do significado que as mães atribuem ao seio, ao lactente, ao ato de amamentar e às circunstâncias sociais e econômicas. (Rodrigues et al., 2017).

Kurtz et al., (2015) aponta que entre esses os principais fatores críticos relacionados às dificuldades no estabelecimento do AM, os relacionados às mães estão: presença de rede de apoio social, prática anterior em amamentação, problemas com a mama e mamilo, (mamilos pouco elásticos, planos, invertidos ou excessivamente longos), bem como aspectos culturais e psicológicos. Já os relacionados aos recém-nascidos estão as disfunções orais e comportamento.

As disfunções orais são desordens no padrão de sucção dos recém-nascidos que refletem no desenvolvimento motor oral e prejudicam a amamentação. Conforme Valério, Araújo e Coutinho (2010), são causadas por alteração na cavidade oral do recém-nascido, ou seja, em seus músculos e/ou estruturas do sistema estomatognático, tais como:

- Ausência de vedamento labial no peito;

- Ausência de reflexo de procura;

- Movimentos mandibulares restritos;

- Língua posteriorizada e

- Incoordenação do ritmo adequado de sucção/respiração/deglutição.

Sanches (2004), aponta que podem ocorrer ainda, alterações de natureza anatômica no funcionamento oral como:

- Palato mais alto;

- Mandíbula mais retraída;

- Freio lingual encurtado ou totalmente fixo e

- Anquiloglossia.

Os bebês com disfunções orais necessitam de aprendizagem e muita habilidade para sugar o seio materno, sendo necessário intervenção fonoaudiológica precoce mediante as primeiras dificuldades durante o estabelecimento do AM para auxiliar os bebês a realizarem adequadamente a pega e a extração do leite da mama de suas mães.

O estudo de Sanches, (2004) ressalta também, que:

Embora as disfunções orais sejam passíveis de serem revertidas precocemente, as ações entre mãe/bebê nas primeiras mamadas rapidamente se tornam hábitos bem estabelecidos, difíceis de mudar, principalmente em relação ao padrão 
de sucção do RN. Por esse motivo, a avaliação detalhada da mamada e ações específicas para a correção de alterações são muito importantes logo no início da amamentação.

Assim, em casos de disfunções orais, é indispensável uma anamnese específica, a avaliação dos aspectos do sistema sensório motor oral e a avaliação da mamada, que permitem que o profissional da saúde identifique aspectos anatômicos e fisiológicos mãe-recém-nascido, tais como: padrão de sucção ineficiente, pega inadequada e incoordenação dos movimentos de sucção-deglutição-respiração.

É necessário o apoio e auxílio de profissionais especializados para atuar de imediato, diagnosticando e intervindo nas desordens funcionais desse sistema, visando o reequilíbrio das funções do sistema estomatognático, levando-se em conta que tais dificuldades podem implicar no desmame precoce quando não tratadas corretamente. (Valério, Araújo \& Coutinho, 2010).

O estudo de Almeida, Luz e Ued (2015) revelou que a amamentação é um desafio também para os profissionais de saúde, que precisam entender os mitos e crenças relacionados ao aleitamento materno, assim como reconhecer os medos, expectativas e a individualidade de cada mãe.

Mostra-se necessário então, um suporte consistente e uma equipe de profissionais de saúde envolvidos em projetos e intervenções que apoiem as mães e familiares desde o período pré-natal até o período de alta hospitalar para facilitar o manejo clínico da amamentação, se obter sucesso na prática e aumento das taxas e duração da amamentação (Almeida, Luz \& Ued, 2015, Kurtz et al., 2015).

É fundamental que nessa equipe esteja inserido um Fonoaudiólogo para o esclarecimento de dúvidas e suporte frente às dificuldades que venham a aparecer nesta etapa. (Rodrigues et al., 2017). Esta parceria é de suma importância para saúde infantil, visto que o fonoaudiólogo tem atuação direta nos primeiros dias de vida do RN, no papel de propiciar melhora no padrão do aleitamento natural, tendo em vista o desenvolvimento ósseo e muscular do sistema estomatognático, em razão da intensa atividade muscular da região peribucal (Medeiros et al., 2017).

O fonoaudiólogo irá agir nas desordens dessas funções, pois está habilitado para intervir no sistema motor oral do bebê, identificando e avaliando precocemente possíveis disfunções orais, como a desordens da sucção do bebê, que podem ser transitórias do próprio funcionamento ou anatômicas (Escarce et al., 2013; Rocha, 2013).

Porém, Medeiros (2015), verificou em sua pesquisa que as gestantes possuíam pouco conhecimento sobre a Fonoaudiologia na saúde materno-infantil e não relacionavam a fonoaudiologia ao aleitamento materno. Descreveu ainda, que na literatura, encontram-se poucos estudos sobre o conhecimento das mães referente ao aleitamento materno e relação com a saúde fonoaudiológica do bebê.

Mediante ao exposto, estudos reforçaram a importância do planejamento de ações para a promoção e a prática do aleitamento, na qual o fonoaudiólogo é um profissional imprescindível, apesar de ainda estar pouco inserido nas equipes multidisciplinares, UTI’s e maternidades (Almeida, Luz \& Ued, 2015, Kurtza et al. 2015).

\section{Considerações Finais}

Diante dos achados, constatou-se os principais desafios para o estabelecimento do aleitamento materno saudável, no qual evidenciou-se que as disfunções orais podem ser identificadas precocemente mediante anamnese dirigida e avaliação oral, que deve ser realizada por um fonoaudiólogo, profissional com experiência no manejo clínico da amamentação e conhecimento do sistema sensório motor-oral do recém-nascido.

Salienta-se ainda que Fonoaudiologia e a Amamentação proporcionam uma parceria que contribui significativamente para o desenvolvimento materno infantil, no entanto, necessita-se de mais estudos demonstrando os benefícios da intervenção fonoaudiológica no AM e como o fonoaudiólogo é primordial no apoio às mães e bebês durante esse processo. É de extrema 
necessidade que esse profissional esteja inserido em ações de promoção ao AM desde o período gestacional até o momento da alta hospitalar, quando não houverem mais dúvidas, dificuldades ou disfunções que interfiram no AM.

Portanto, considera-se alcançado o objetivo da revisão e sugere-se que sejam realizadas mais pesquisas sobre a intervenção fonoaudiológica no aleitamento materno ressaltando ainda mais a importância de atuação profissional nesta área.

\section{Referências}

Almeida, J. M., Luz, B, S. A., \& Veiga, F. (2015). Apoio ao aleitamento materno pelos profissionais de saúde: revisão integrativa da literatura. Rev. paul. pediatr. 33(3), 355-362.

Araújo, O. D., Cunha, A. L., Lustosa, L. R., Nery, I. S., Mendonça, R. C. M., \& Campelo, S. M. A. (2008). Aleitamento Materno: fatores que levam ao desmame precoce. Rev. Bras. Enferm. 61(4), 488-92

Bezutti, S., \& Giustina A. (2017). A importância do aleitamento materno exclusivo até os seis meses de idade. Pubmed.

Escarce, A. G., Araújo, N. G., Friche, A. A. L., \& Motta, A. R. (2013). Influência da orientação sobre aleitamento materno no comportamento das usuárias de um hospital universitário. Rev. CEFAC. 15(6), 1570- 1582.

Kurtz, L., Maahs, M. A. P., Bonamigo A. W., \& Almeida, S. T. (2015). Promoção do aleitamento materno em um contexto interdisciplinar. Rev. de Atenção à Saúde. 13(43), 46-52.

Martins, R. F. M., Filho, R. H. L. L., Fernandes, F. S. F. \& Fernandes J. K. B. (2012). Amamentação e fatores relacionados ao desmame precoce: uma revisão crítica da literatura. Rev. Pesq. Saúde. 13(3), 47-52.

Medeiros, A. M. C., Alves, Y. V. T., Santos, J. C. J., Santos, D. A. R., Santos, K. C. F., Rocha, P. B., \& Anjos, T. M. B. (2015). Acompanhamento da efetividade do aleitamento materno após 24 horas da intervenção fonoaudiológica. XXIII Congresso Brasileiro e IX Congresso Internacional de Fonoaudiologia, BA, Brasil.

Medeiros, A. M. C., Batista, B. G., \& Barreto, I. D. C. (2015). Aleitamento materno e aspectos fonoaudiológicos: conhecimento e aceitação de mães de uma maternidade. Audiol Commun Res. 20(3),183-90.

Medeiros, A. M. C., Santos, J. C. J., Santos, D. A. R., Barreto, I. D. C., \& Alves, Y. V. T. (2017). Acompanhamento fonoaudiológico do aleitamento materno em recém-nascidos nas primeiras horas de vida. Audiol Commun Res.

Mendes, K. D. S., Silveira, R. C. C. P., \& Galvão, C. M. (2008). Revisão integrativa: método de pesquisa para a incorporação de evidências na saúde e na enfermagem. Texto Contexto Enferm. 17(4), 758-64

Pontes, A. M., Lucena, K. D. T., Silva, A. T. M. C., Almeida., L. R. \& Deininger, L. S. C. (2013) As repercussões do aleitamento materno exclusivo em crianças com baixo peso ao nascer. Saúde debate. 37(97).

Rodrigues, G., Dias, D., \& Marques, V. (2017) O fonoaudiólogo no incentivo do aleitamento materno nas maternidades. Revista Digital Acadêmica CREFONO1. (3a ed.).

Sanches, M. T. C. (2004) Manejo clínico das disfunções orais na amamentação. J. Pediatr. 80(5) suppl.

Scheeren, B., Mengue, A. P. M., Devincenzi, B. S., Barbosa, L. R. \& Gomes, E. (2012) Condições iniciais no aleitamento materno de récem-nascidos prematuros. J. Soc. Bras. Fonoaudiol. São Paulo. 24(3), 199-204.

Souza, M. T., Silva, M. D., \& Carvalho, R. (2010) Revisão integrativa: o que é e como fazer Integrative review: what is it? How to do it? Einstein. 8(1), 102106.

Valério, K. D., Araújo, C. M. T., \& Coutinho, S. B. (2010) Influência da disfunção oral do neonato a termo sobre o início da lactação. Rev. CEFAC. 12(3).

Neves, D. C., Aguiar, A. M. A, \& Andrade, I. S. N. (2007) O conhecimento de gestantes adolescentes sobre fonoaudiologia relacionada a saúde maternoinfantil. RBPS. 20(4), 207-212.

Pereira, A. S., Shitsuka, D. M., Parreira, F. J. \& Shitsuka, R. (2018). Metodologia da pesquisa científica. Universidade Federal de Santa Maria. 